\title{
THE HAEMOGREGARINES OF MAMMALS AND REPTILES.
}

\author{
By Captain W. S. PATTON, M.B. Edin., I.M.S.
}

(From the Quick Laboratory, Cambridge.)

IN two recent papers, Sambon and Seligmann (1907, 1908) have recorded some observations on the intracellular parasites of snakes, and have described no less than ten new species. The authors, in discussing the life histories of these parasites, have made the startling discovery that, "the life history of the haemogregarines like that of the haemoprotozoa is divided into two cycles: a schizogonic or 'vegetative' cycle spent in the blood of vertebrates and characterised by asexual multiplication, and a sporogonic or sexual cycle spent in the digestive organs of blood-sucking invertebrates and characterised by sexual reproduction." The authors then go on to speak quite familiarly of young merozoites, adult schizonts, adult sporonts, and so on.

My excuse for making some remarks on their findings is the fact that since November, 1905, up till July, 1908, I have worked with the following snakes infected with haemogregarines:

$\begin{array}{ll}\text { Bungarus coeruleus (candidus) } & \text { Eryx johnii } \\ \text { Vipera russellii } & \text { Gonglyophis conicus } \\ \text { Naja tripudians } & \text { Dryophis mycterizans } \\ \text { Python molurus } & \text { Dendrophys pictus } \\ \text { Zamenis mucosus } & \text { Tropidonotus piscator } \\ & \text { Tropidonotus stolatus }\end{array}$

In all 250 snakes were at one time or another in the Laboratory at the King Institute, Madras, the majority of which harboured two species of Aponomma: A.gervaisi and another species not yet identified. Careful feeding experiments with the larvae, nymphs and adults of both these ticks were carried out in special receptacles, so that the conditions were very much as they occur in nature. In addition, I have had the 
opportunity of studying no less than five haemogregarines in Rana tigrina and Rana hexydactyla, not only in the frogs but in the leech which transmits them. I have also studied the haemogregarine of Emyda granosa both in the tortoise and in the transmitting leech.

Lastly, I have had the unique opportunity of studying three mammalian Leucocytozoa: L. funambuli, L. felis domestici and L. leporis. With this large material at my disposal I have made an exhaustive effort to trace out the extracorporeal life histories of these intracellular parasites of mammals and reptiles, but in every case I have failed to find any developmental cycle in the corresponding blood-sucking invertebrates. In the case of the leech from Emyda granosa, Christophers once showed me some bodies which suggested developmental forms of the haemogregarine of the tortoise; I have examined these parasites in the leech, but can only come to the conclusion that they probably represent some stage in the life cycle of a Coccidium parasitic in the leech.

A few observations on $L$. leporis in the tick Haemaphysalis flava have suggested to me that the method of transmission of these parasites will eventually prove to be mechanical and that the characteristic vermicules,- -whose sex, by the way, I am at present unable to determine,free thenselves in the intestinal tracts of the various invertebrate hosts and in some manner at present unknown make their way back to the biting parts. I have actual experimental evidence proving that the vermicules of $L$. leporis can remain alive in the alimentary tract of larvae and nymphs of $H$. flava for at least 15 days.

I am at a loss, therefore, to understand how Sambon and Seligmann have been able to observe adult sporonts, schizonts, etc., and how they are in a position to state these parasites have a sporogonic cycle in invertebrate hosts. It remains to be seen what observations they have made on the curious cycle found in the lungs and liver of snakes infected with haemogregarines. I have examined many examples of all the stages of this cycle not only in the stained condition but particularly in the fresh condition (for 12 hours) in the lung of Zamenis mucosus, and I have not been able to satisfy myself as to whether this cycle of multiplication is an asexual or sexual process; for this reason I could not definitely say what the different forms seen in the peripheral blood of all my snakes really represented. Yet I find Sambon and Seligmann call some of these merozoites, others adult schizonts, sporonts, etc. As far as I can gather they have principally studied these parasites in the peripheral blood of snakes, so that I cannot see their grounds 
for these statements. Further, I would point out that I have examined haemogregarines in eight different genera of snakes and from a study of the parasites not only in the peripheral blood but also in the organs, I believe they belong to the same species. On the contrary Sambon and Seligmanu make every haemogregarine they see in different species of snakes' peripheral blood a new species even in spite of the fact that they studied the parasites in this country when probably not a single snake had a tick on it. Without infecting a snake through the agency of the right tick and then studying the various forms of the parasites that appear in the blood and the organs of the snake, I do not see how it is possible to speak of the parasites in the peripheral blood as schizonts, sporonts, etc.

During the $2 \frac{1}{2}$ years I have studied these intracellular parasites I have not felt myself justified in recording the results of my observations, as I considered my work would in no way advance our knowledge of these parasites, but after reading Sambon and Seligmann's papers I feel it is right $I$ should record them, even though they are negative. Many keen observers in the tropics just beginning the study of these parasites and with excellent material at hand, on reading Sambon and Seligmann's papers, may come to the conclusion that there is nothing new to be learnt about them. I would like to advise them that this is not the case and that in my opinion the work of Sambon and Seligmann, instead of adding to our knowledge of these parasites, has increased the confusion already existing.

Note. While the above article was in the press a paper by Prowazek came to my notice. Prowazek speaks of free vermicules and cysts having a membrane with a double contour. The parasites he describes occurred in the Pentastome from a Python infected with Haemogregarina pythonis. He suggests that the cysts represent a further development of the haemogregarine. In November 1905, I examined a large number of Pentastomes (Porocephalus pattoni, Stephens) which are very common in the lungs of the rat snake Zamenis mucosus and found they were infected with what I then thought represented developmental forms of the haemogregarine of the snake. In addition to many free vermicules the Pentastomes contained cysts with a membrane having a double contour and containing smaller cysts full of spindle shaped bodies. I now know these cysts represent part of the cycle of a parasite peculiar to the Pentastome and have nothing to do with the haemogregarine of the snake. 


\section{REFERENCES.}

ProwazeK, S. (29. Ix. 1908). Ueber Haemogregarinen aus Porocephalus moniliformis. (Zool. Anzeiger, xxxIII. 465, 466, Fig.)

Sambon, L. W. and Seliamann, C. G. (10. vi. 1907). Haemogregarines in snakes. [Proceedings Patholog. Society.] Lancet, I. p. 1650.

Sambon, L. W. and Seligmann, C. G. (1. xir. 1908). The Haemogregarines of snakes. Journal of Tropical Medicine, pp. 355-358, 1 Fig. (to be continued). 